(1]

Dept of Pediatric Pulmonology, Katholieke Universiteit Leuven, Leuven, Belgium.

\section{Respiratory illness in children with disability: a serious problem?}

\section{Introduction}

Children with severe neurocognitive impairment often present to paediatric clinics with recurrent and chronic lower airway infections and increased risk of respiratory insufficiency [1]. These pulmonary problems play an important role in the morbidity and even the mortality of children with neurocognitive impairment [2-5]. However, the impact may be insufficiently recognised by caregivers and doctors, and the medical literature pays relatively little attention to this topic. Studies are scarce and often involve retrospective data from small cohorts. This is most likely because studies are not easy to set up in this population and the complexity of setting up studies on, for example, pneumonia occurrence and risk factors have been well described [6].

\section{Epidemiology}

The prevalence of lower airway infections in children with neurocognitive and motor impairment have mainly been studied in specific conditions such as cerebral palsy $[5,6]$ or in well-defined subgroups like children with disability referred for gastrostomy or because of feeding problems [7, 8]. In an Australian cerebral palsy registry, respiratory problems were very common, with daily cough or wheeze in $58 \%$, obstructive sleep apnoea in 10\%, cough with drinking in $40 \%$ and abnormalities on clinical pulmonary exam in around 20\% [9]. Children with cerebral palsy have an increased risk of sudden death during sleep and most of these patients have a cluster of respiratory problems such as recurrent aspiration pneumonia, chronic bronchitis and (nocturnal) respiratory insufficiency [10]. Pneumonia may disproportionally contribute to mortality in cerebral palsy and some data suggest that pneumonia was responsible for $40 \%$ of all deaths [9].

We studied the respiratory morbidity in more than 120 children with profound intellectual and multiple disability in the setting of specialised care centres [11]. Almost all patients were classified as Gross Motor Function Classification System (GMFCS) class 4-5, and one out of four had a diagnosis of cerebral palsy. The median number of lower airway infections per year was less than anticipated (4, interquartile range 1-4). Around $12 \%$ of patients had three or more hospital admission for respiratory illnesses in the previous 5 years, again lower than expected from our hospital experience. We hypothesise that in hospital, we mainly treat a small subgroup of children with neurocognitive impairment needing recurrent inpatient respiratory care while the majority of these children are never seen in the acute hospital setting. However, around $25 \%$ of patients had some form of chronic respiratory treatment (i.e. mucolytics, nebulised inhaled corticosteroids or bronchodilators, chest physiotherapy, or long-term antibiotics) reflecting significant chronic respiratory morbidity.
Cite as: Proesmans $M$. Respiratory illness in children with disability: a serious problem? Breathe 2016; 12: e97-e103. 
In a study of children with cerebral palsy referred for gastrostomy, the median number of antibiotic treatments over a 6 months period was 1.8 and the median number of hospital admissions for respiratory reasons was $<1$ [8]. In a group of 34 children with severe disability and feeding problems, however, only 10 did not have respiratory infections at all and 16 had severe lower airway infections [7]. However, the latter preselected groups cannot be compared to our group.

\section{Risk factors and underlying causes}

The underlying causes for respiratory illness in children with neurocognitive impairment are multiple and in most children, several risk factors are simultaneously present (figure 1). Most risk factors are only recognised based on clinical experience [12] and again, limited research has been done in this field.

\section{Kyphoscoliosis}

Children with cerebral palsy and other neurological problems are prone to develop musculoskeletal deformities. The underlying neurological insult may results in a loss of selective motor control, an increase in underlying muscle tone and muscle imbalance, which can lead to abnormal deforming forces acting on the immature skeleton [13]. Kyphoscoliosis can lead to mechanical disadvantage of the respiratory muscles and decrease the chest wall compliance. If present in early childhood, kyphoscoliosis can also limit lung growth. The net effect is an increased respiratory effort, decreased vital capacity and unequal lung ventilation resulting in risk of respiratory failure [12, 14]. In a study on children and adults with severe neurological impairment, kyphoscoliosis was one of the major factors predicting increased endtidal carbon dioxide, a measure of respiratory ventilator insufficiency [15]. Occasionally, severe kyphoscoliosis can lead to airway compression by the displaced spine [16].

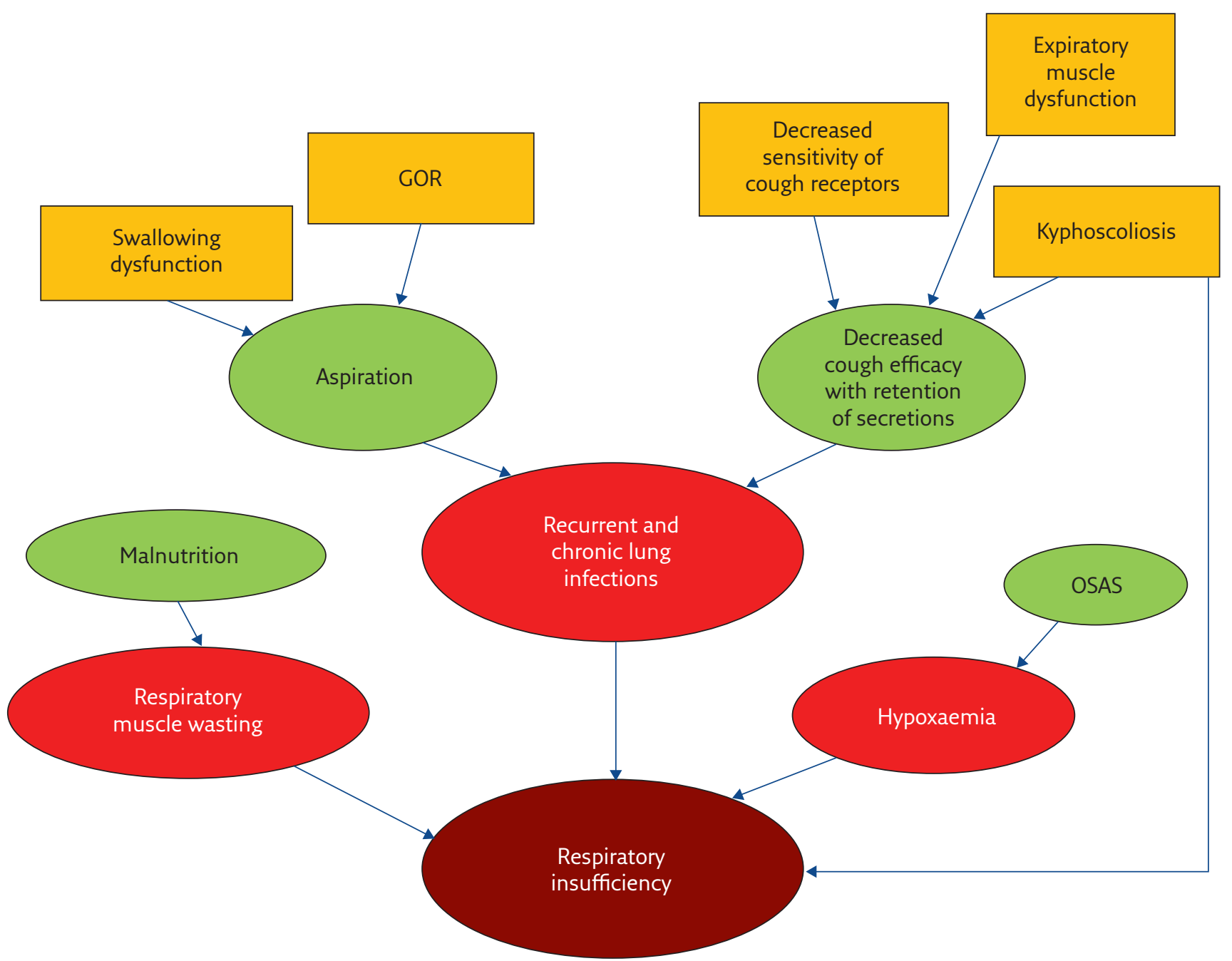

Figure 1 Riskfactors for respiratory illness in children with disability. GOR: gastro-oesophageal reflux; OSAS: obstructive sleep apnoea syndrome. 


\section{Gastro-oesophageal reflux, swallowing and aspiration}

An important risk factor for chronic lower airway infections and recurrent pneumonia is aspiration, either secondary to dysphagia and swallowing dysfunction or secondary to gastro-oesophageal reflux (GOR) [17-23]. For evaluation of swallowing function and possible aspiration, different tests are used in addition to clinical observation: barium video fluoroscopy, salivagram and milk scanning. Milk scanning is the least sensitive and overall, the agreement between these tests in poor $[24,25]$. Children with abnormal findings on a salivagram have a high rate of abnormal findings on chest radiography suggestive of lung disease secondary to chronic aspiration [26]. For more advanced evaluation, combination of video fluoroscopy and swallow manometry is suggested [27]. For evaluation of GOR, 24-h pH studies, preferably with impedance and oesophagogastroscopy, are the gold standard [23].

\section{Cough}

For efficient clearing of airway secretions and for protection against aspiration, an effective cough is necessary. This requires good coordination and timing of expiratory and glottis muscles [12]. Many patients with neurocognitive impairment have no spontaneous cough or an insufficiently forceful cough.

\section{Upper airway obstruction}

Obstructive breathing due to upper airway obstruction (UAO) is a common problem in children with neurological impairment, especially in the context of cerebral palsy. The main cause is loss of muscle tone of the pharynx which, during sleep, can lead to sleep disordered breathing, hypercarbia and hypoxaemia with risk of pulmonary hypertension [28].

The prevalence of UAO in a cohort of hospitalised children from South Africa with cerebral palsy was $8.8 \%$. Epilepsy, feeding complications and severe physical disability are associated with UAO in this cohort of children with cerebral palsy (R. Petersen, Red Cross Hospital, Cape Town, South Africa; personal communication).

\section{Chronic airway colonisation and infection}

A paediatric intensive care unit (ICU)-based study demonstrated an association between Pseudomonas aeruginosa lung infections in cerebral palsy patients and morbidity [29]. Children with cerebral palsy and isolation of $P$. aeruginosa or other Gram-negative bacteria from airway cultures had an increased frequency of ICU admissions, intubation and large pleural effusion. Additionally, they had more prolonged hospitalisations and were more at risk for multiple hospitalisations [30].

\section{General risk factors}

The clinician should not forget to look for common causes of recurrent or chronic airway problems in this specific group. Asthma, passive smoke exposure and immobility as well as immunodeficiency should not be overlooked.

In our cohort study, a wide range of risk factors were identified and many patients had a combination of several risk factors. As could be expected, GOR, swallowing problems and aspiration increased the risk of hospital admissions. Other risk factors were axial hypotonia, epilepsy, scoliosis and absence of spontaneous cough reflex [11].

\section{Treatment}

\section{Chest physiotherapy}

While in paediatric neuromuscular disorders, the use of chest physiotherapy with specific devices has been well studied, the literature on this topic in cerebral palsy and other neurocognitive impairment is scant [31-34]. Interventions such as cough assist devices and intrapulmonary percussion are now commonly used in neuromuscular patients for prevention and treatment of lower airway infections and impaction of secretions. One of the few studies on chest physiotherapy in cerebral palsy investigated the use of high-frequency chest wall compression (Vest system; Hill-Rom, Amsterdam, the Netherlands) in a prospective, uncontrolled study in seven patients with cerebral palsy (five with a tracheostomy). The total number of pneumonia episodes and antibiotic courses decreased significantly, as did the pneumoniaassociated hospital admissions [35]. Another study also showed that the use of the Vest technique for chest physiotherapy reduced the number of hospital admissions in children with cerebral palsy or neuromuscular disease compared to controls [36]. A recent Cochrane review on this topic concluded that although the available studies consider different treatments methods, potential benefits were found for most the interventions in the absence of adverse events [37].

Based on clinical experience, chest physiotherapy is an important tool to treat children with inefficient cough and chronic or recurrent lower airway infections. A recent abstract reported on the impact of home based respiratory physiotherapy service with a significant decrease in emergency visits and hospital admission in children with neurodevelopmental and muscular disorders [38].

\section{Gastrostomy feeding}

The main indication for gastrostomy feeding is unsafe swallowing with risk for aspiration. In case of failure of medical management of additional GOR, this may be combined with an antireflux procedure. 


\section{Self-evaluation questions}

1 Which of the following respiratory problems are common in children with cerebral palsy or other disabilities?

a) Obstructive sleep apnoea.

b) Asthma (more than in the general population).

c) Cough with drinking.

d) Chronic bronchitis.

e) Recurrent pneumonia.

f) Foreign body aspiration.

g) All of the above.

2 To assess the risk of aspiration in children with disability, which of the following examinations would you prefer?

a) Barium fluoroscopy and 24-h pH study.

b) Milk scan only.

c) Oesophageal manometry only.

3 The development of kyphoscoliosis:

a) has no respiratory impact; it only affects posture and positioning.

b) only leads to reduction of lung volume.

c) leads to lung restriction, unequal ventilation and decreased cough efficacy.

4. First line treatment for obstructive sleep apnoea syndrome in the context of disability consist of:

a) tracheostomy.

b) nasal continuous positive airway pressure.

c) avoiding medication that reduces muscle tone.

d) adenotonsillectomy and sleep positioning. our institution, 106 consecutive patients referred for a laparoscopic Nissen procedure were evaluated (57 neurologically normal and 49 neurologically impaired). Mortality was $0 \%$ and conversion rate to laparotomy was $2.8 \%$. Major post-operative complications occurred in 12 patients, mostly with neurologically impairment [40].

While gastrostomy feeding prevents aspiration of food, it does not prevent the aspiration of saliva and upper airway secretions. Some centres opt for surgical closure of the larynx in cases of intractable aspiration [41] and recently, novel surgical closure techniques with a lower risk of complications have been described [42]. In our centre, we have no experience with these surgical techniques in children, and the decision is not easy because it implicates loss of phonation and the presence of a permanent tracheostomy.

Hypersalivation is a common finding in children with neurodevelopmental problems and this may increase the risk of aspiration. Apart from medical treatment options (hyoscine and glycopyrrolate), botulinum toxin injections in the salivary gland or surgical gland resection are effective treatment options [43, 44].

\section{Scoliosis surgery}

In many centres, children with severe and progressive scoliosis in the context of severe disability are referred for spinal surgery. Although neuromuscular scoliosis surgery may improve the scoliosis curve, evidence that it prolongs survival is lacking. Furthermore, in the severely impaired child, the ethical dilemma of whether to subject the child to an extremely painful, complicationprone procedure involving a prolonged hospital stay needs to be carefully considered. In a recent metaanalysis, neuromuscular scoliosis patients have diverse and high complication rates after scoliosis surgery, with $30 \%$ of children with cerebral palsy having respiratory complications [45]. In a survey performed in our centre, almost $50 \%$ of children with cerebral palsy developed a pneumonia or atelectasis post-surgery and $20 \%$ had woundrelated issues. There was, however, no surgeryrelated mortality (unpublished data).

Unfortunately, qualitative data on long-term outcome (i.e. comparing quality of life (QOL) and survival with or without surgery) are, to my knowledge, not available. Some reports describe very subjective and descriptive results after spinal fusion of improved sitting position, fewer pressure sores and subjectively better breathing, for example, in patients with Rett syndrome [46]. In a retrospective cohort, spinal fusion improved the activity and participation as assessed by the caregiver, while mobility, feeding, GMFCS level and communication did not change [47].

A questionnaire-based study reported positive effects on overall function, QOL and ease of care as evaluated by the parents, and improved motor 
function reported by the therapist [48]. Data on change in respiratory outcome are scarce. In one retrospective cohort, lifetime pneumonia risk was related to epilepsy, non-cerebral palsy causes and major scoliosis. However, the yearly incidence of pneumonia did not decrease after spinal surgery [49]. In a recently published retrospective cohort with early onset neuromuscular scoliosis, spinal fusion was associated with minimal shortand long-term morbidity, but there was $28 \%$ mortality at 10 -year follow-up and $50 \%$ predicted mortality at 15 years $[47,50]$.

\section{Upper airway obstruction}

Treatment for obstructive sleep apnoea syndrome (OSAS) is stepwise in children with neurocognitive impairment. Adenotonsillectomy may be considered in this context as a first step, together with sleep position (prone or on the side rather than on the back) as a second step. Rapid weight increase may aggravate OSAS and excessive weight gain after the start of gastrostomy feeding should be avoided. Changes in medication for epilepsy or spasticity may also increase pharyngeal hypotonia and/or upper airway secretions, and thus OSAS. Some centres have had positive experiences with the use of nasopharyngeal airways in this context. Start of nasal continuous positive airway pressure (nCPAP) may be considered but should be carefully weighed against the increased burden of care, increased cost and possible side-effects. Data on improved QOL or daytime functioning after the start of nCPAP in this group are largely missing. One small study (with only three children with nCPAP) documented improved QOL and daytime function (compared with a control group without OSAS diagnosis) [51]. In cases of severe obstructive breathing, a tracheostomy may be considered [52]. Again, this should be carefully set against the drawbacks of a tracheostomy increasing the complexity and intensity of the care.

\section{Conclusion}

Children with neurocognitive impairment often present with chronic or recurrent respiratory problems, which have an important impact on QOL and life expectancy. The underlying causes are multiple, ranging from risk of aspiration, insufficient cough and UAO to progressive kyphoscoliosis. Concomitant disease such as asthma or immunodeficiency should not be overlooked. There is often a complex interplay between these known risk factors. The diagnostic and therapeutic approach should be multidisciplinary and decisions for treatment should be individualised, aiming to improve the QOL of the child. Advanced care planning in children with neurocognitive disability should not only concentrate on intellectual development, motor function, orthopaedic aspects and feeding, but also on the respiratory problems that may be encountered [53].

\section{Conflict of interest}

None declared.

\section{References}

1. Mahon M, Kibirige MS. Patterns of admissions for children with special needs to the paediatric assessment unit. Arch Dis Child 2004; 89: 165-169.

2. Hollins S, Attard MT, von Fraunhofer N, et al. Mortality in people with learning disability: risks, causes, and death certification findings in London. Dev Med Child Neurol 1998; 40: 50-56.

3. Plioplys AV, Kasnicka I, Lewis $S$, et al. Survival rates among children with severe neurologic disabilities. South Med J 1998; 91: 161-172.

4. Westbom L, Bergstrand L, Wagner P, et al. Survival at 19 years of age in a total population of children and young people with cerebral palsy. Dev Med Child Neurol 2011; 53: 808-814.

5. Young NL, McCormick AM, Gilbert T, et al. Reasons for hospital admissions among youth and young adults with cerebral palsy. Arch Phys Med Rehabil 2011; 92: 46-50.

6. Veugelers R, Calis EA, Penning C, et al. A population-based nested case control study on recurrent pneumonias in children with severe generalized cerebral palsy: ethical considerations of the design and representativeness of the study sample. BMC Pediatr 2005; 5: 25.

7. Morton RE, Wheatley R, Minford J. Respiratory tract infections due to direct and reflux aspiration in children with severe neurodisability. Dev Med Child Neurol 1999; 41: 329-334.

8. Sullivan PB, Morrice JS, Vernon-Roberts A, et al. Does gastrostomy tube feeding in children with cerebral palsy increase the risk of respiratory morbidity? Arch Dis Child 2006; 91: 478-482.

9. Reddihough DS, Baikie G, Walstab JE. Cerebral palsy in Victoria, Australia: mortality and causes of death. J Paediatr Child Health 2001; 37: 183-186.

10. Karatas AF, Miller EG, Miller F, et al. Cerebral palsy patients discovered dead during sleep: experience from a comprehensive tertiary pediatric center. J Pediatr Rehabil Med 2013; 6: 225-231.

11. Proesmans $M$, Vreys $M$, Huenaerts $E$, et al. Respiratory morbidity in children with profound intellectual and multiple disability. Pediatr Pulmonol 2015; 50: 1033-1038.

12. Seddon PC, Khan Y. Respiratory problems in children with neurological impairment. Arch Dis Child 2003; 88: 75-78.

13. Chan G, Miller F. Assessment and treatment of children with cerebral palsy. Orthop Clin North Am 2014; 45: 313-325.

14. Noble-Jamieson CM, Heckmatt JZ, Dubowitz V, et al. Effects of posture and spinal bracing on respiratory function in neuromuscular disease. Arch Dis Child 1986; 61: 178-181.

15. Jacob R, Nelkenbaum A, Merrick J, et al. Capnography in patients with severe neurological impairment. Res Dev Disabil 2014; 35: 1259-1263.

16. Arumainathan R, Morris SA, George M. Torsion of left main bronchus during general anesthesia for posterior instrumented spinal fusion. Clin Case Rep 2016; 4: 633-635.

\section{Suggested answers}

1. a, c, d and e.

2. a.

3. c.

4. d. 
17. Arvedson J, Rogers B, Buck G, et al. Silent aspiration prominent in children with dysphagia. Int J Pediatr Otorhinolaryngol 1994; 28: 173-181.

18. Calis EA, Veugelers R, Sheppard J, et al. Dysphagia in children with severe generalized cerebral palsy and intellectual disability. Dev Med Child Neurol 2008; 50: 625-630.

19. Casas MJ, Kenny DJ, McPherson KA. Swallowing/ ventilation interactions during oral swallow in normal children and children with cerebral palsy. Dysphagia 1994; 9: 40-46.

20. Gustafsson PM, Tibbling L. Gastro-oesophageal reflux and oesophageal dysfunction in children and adolescents with brain damage. Acta Paediatr 1994; 83: 1081-1085.

21. Mirrett PL, Riski JE, Glascott J, et al. Videofluoroscopic assessment of dysphagia in children with severe spastic cerebral palsy. Dysphagia 1994; 9: 174-179.

22. Rogers B, Stratton P, Msall $M$, et al. Long-term morbidity and management strategies of tracheal aspiration in adults with severe developmental disabilities. Am J Ment Retard 1994; 98: 490-498.

23. Boesch RP, Daines C, Willging JP, et al. Advances in the diagnosis and management of chronic pulmonary aspiration in children. Eur RespirJ 2006; 28: 847-861.

24. Baikie G, South MJ, Reddihough DS, et al. Agreement of aspiration tests using barium videofluoroscopy, salivagram, and milk scan in children with cerebral palsy. Dev Med Child Neurol 2005; 47: 86-93.

25. Yang J, Codreanu I, Servaes S, et al. Radionuclide salivagram and gastroesophageal reflux scintigraphy in pediatric patients: targeting different types of pulmonary aspiration. Clin Nucl Med 2015; 40: 559-563.

26. Drubach LA, Zurakowski D, Palmer EL 3rd, et al. Utility of salivagram in pulmonary aspiration in pediatric patients: comparison of salivagram and chest radiography. AJR Am Roentgenol 2013; 200: 437-441

27. Rommel N, Omari T. Abnormal pharyngoesophageal function in infants and young children: diagnosis with highresolution manometry. J Pediatr Gastroenterol Nutr 2011; 52 Suppl. 1, S29-S30.

28. Kotagal S, Gibbons VP, Stith JA. Sleep abnormalities in patients with severe cerebral palsy. Dev Med Child Neurol 1994; 36: 304-311.

29. Thorburn K, Jardine M, Taylor N, et al. Antibioticresistant bacteria and infection in children with cerebral palsy requiring mechanical ventilation. Pediatr Crit Care Med 2009; 10: $222-226$

30. Gerdung CA, Tsang A, Yasseen AS 3rd, et al. Association between chronic aspiration and chronic airway infection with Pseudomonas aeruginosa and other Gram-negative bacteria in children with cerebral palsy. Lung 2016; 194: 307-314.

31. Chatwin M, Bush A, Simonds AK. Outcome of goaldirected non-invasive ventilation and mechanical insufflation/ exsufflation in spinal muscular atrophy type I. Arch Dis Child 2011; 96: 426-432.

32. Chatwin M, Simonds AK. The addition of mechanical insufflation/exsufflation shortens airway-clearance sessions in neuromuscular patients with chest infection. Respir Care 2009; 54: 1473-1479.

33. Strickland SL, Rubin BK, Drescher GS, et al. AARC clinical practice guideline: effectiveness of nonpharmacologic airway clearance therapies in hospitalized patients. Respir Care 2013; 58: 2187-2193.

34. Keating JM, Collins N, Bush A, et al. High-frequency chest-wall oscillation in a noninvasive-ventilation-dependent patient with type 1 spinal muscular atrophy. Respir Care 2011 56: 1840-1843

35. Plioplys AV, Lewis S, Kasnicka I. Pulmonary vest therapy in pediatric long-term care. J Am Med Dir Assoc 2002; 3: 318-321.

36. Yuan N, Kane P, Shelton K, et al. Safety, tolerability, and efficacy of high-frequency chest wall oscillation in pediatric patients with cerebral palsy and neuromuscular diseases: an exploratory randomized controlled trial. J Child Neurol 2010; 25: 815-821.

37. Winfield NR, Barker NJ, Turner ER, et al. Nonpharmaceutical management of respiratory morbidity in children with severe global developmental delay. Cochrane Database Syst Rev 2014; CD010382.

38. Johnstone Z UD, Noone L, Dhouieb. A service evaluation of rapid response domicilary respiratory physiotherapy in children with complex needs. Arch Dis Child 2016; 101: Suppl. 1, A311.

39. Livingston $\mathrm{MH}$, Shawyer $\mathrm{AC}$, Rosenbaum $\mathrm{PL}$, et al. Fundoplication and gastrostomy versus percutaneous gastrojejunostomy for gastroesophageal reflux in children with neurologic impairment: a systematic review and metaanalysis. J Pediatr Surg 2015; 50: 707-714.

40. Mathei J, Coosemans W, Nafteux P, et al. Laparoscopic Nissen fundoplication in infants and children: analysis of 106 consecutive patients with special emphasis in neurologically impaired vs. neurologically normal patients. Surg Endosc 2008; 22: 1054-1059

41. Takano K, Kurose M, Mitsuzawa $\mathrm{H}$, et al. Clinical outcomes of tracheoesophageal diversion and laryngotracheal separation for aspiration in patients with severe motor and intellectual disability. Acta Otolaryngol 2015; 135: 1304-1310.

42. Ise K, Kano M, Yamashita M et al. Surgical closure of the larynx for intractable aspiration pneumonia: cannula-free care and minimizing the risk of developing trachea-innominate artery fistula. Pediatr Surg Int 2015; 31: 987-990.

43. Formeister EJ, Dahl JP, Rose AS. Surgical management of chronic sialorrhea in pediatric patients: 10-year experience from one tertiary care institution. Int J Pediatr Otorhinolaryngol 2014: 78: 1387-1392.

44. Mahadevan M, Gruber M, Bilish D, et al. Botulinum toxin injections for chronic sialorrhoea in children are effective regardless of the degree of neurological dysfunction: A single tertiary institution experience. Int J Pediatr Otorhinolaryngo 2016; 88: 142-145.

45. Sharma S, Wu C, Andersen T, et al. Prevalence of complications in neuromuscular scoliosis surgery: a literature meta-analysis from the past 15 years. Eur Spine J 2013; 22: 1230-1249.

46. Larsson EL, Aaro S, Ahlinder P, et al. Long-term follow-up of functioning after spinal surgery in patients with Rett syndrome. Eur Spine J 2009; 18: 506-511.

47. Sewell MD, Wallace C, Malagelada F, et al. Does spinal fusion and scoliosis correction improve activity and participation for children with GMFCS level 4 and 5 cerebral palsy? Medicine 2015; 94: e1907.

48. Tsirikos Al, Chang WN, Dabney KW, et al. Comparison of parents' and caregivers' satisfaction after spinal fusion in children with cerebral palsy. J Pediatr Orthop 2004; 24: 54-58.

49. Keskinen $\mathrm{H}$, Lukkarinen $\mathrm{H}$, Korhonen $\mathrm{K}$, et al. The lifetime risk of pneumonia in patients with neuromuscular scoliosis at a mean age of 21 years: the role of spinal deformity surgery. J Child Orthop 2015; 9: 357-364.

50. Sitoula P, Holmes LJr. Sees J, et al. The long-term outcome of early spine fusion for scoliosis in children with cerebral palsy. Clin Spine Surg 2016; 29: E406-E412.

51. Hsiao KH, Nixon GM. The effect of treatment of obstructive sleep apnea on quality of life in children with cerebral palsy. Res Dev Disabil 2008; 29: 133-140.

52. Kontorinis G, Thevasagayam MS, Bateman ND. Airway obstruction in children with cerebral palsy: need for tracheostomy? Int J Pediatr Otorhinolaryngol 2013; 77: 1647-1650.

53. Horridge KA. Advance Care Planning: practicalities, legalities, complexities and controversies. Arch Dis Child 2015; 100: 380-385 